\title{
Canine Cutaneous Mast Cell Tumor: Biologic Behavior and Its Correlation with Prognostic Indicators
}

\author{
Sabrina dos Santos Costa Poggiani ${ }^{1 *}$, Erika Maria Terra ${ }^{2}$, Rafael Torres Neto ${ }^{2}$, Mirela Tinucci Costa ${ }^{2}$, \\ Renée Laufer Amorim ${ }^{2}$ \\ ${ }^{1}$ Department of Veterinary Medicine, Pioneer Union of Social Integration, Brasilia, Brazil \\ ${ }^{2}$ Department of Veterinary Clinics, Veterinary Medicine and Animal Science School, Universidade Estadual Paulista Júlio de \\ Mesquita Filho, Botucatu, Brazil \\ Email: "bina1304@gmail.com, *bina1304@hotmail.com, renee@fmvz.unesp.br
}

Received September 3, 2012; revised October 9, 2012; accepted October 20, 2012

\begin{abstract}
Cutaneous mast cell tumor (MCT) shows a variable biological behavior in dogs and may present either as solitary masse that can be treated and cured with surgical removal or as a systemic metastatic and fatal disease. Histological grade, KIT pattern and proliferative index are typically prognostic factors in MCTs. In the present study, we have investigated correlation between clinical data (breed, age, gender, tumour location, tumor size, time before surgery, number of tumours, occurrence of metastasis and recurrence), cellular proliferation (Ki-67, mitotic index), intratumoural microvessel density (IMVD) and apoptotic index with the histological grade and KIT pattern. 28 tumors, from 20 dogs with cutaneous MCT were evaluated. There was association between histological grade, IMVD, tumor ulceration and number of tumors. A significant increase of Ki-67 expression and mitotic index was observed in MCTs with cytoplasmic KIT staining pattern. Patnaik histological grade system was related to mitotic index. Histological grade in canine cutaneous MCT should not be assessed as the only prognostic factor, but associated with KIT pattern, IMDV, cellular proliferation, presence of tumour ulceration, number of tumours, recurrences and metastases.
\end{abstract}

Keywords: Dog; Mast Cell Tumor; Prognosis; Biologic Behavior

\section{Introduction}

MCT is the most common malignant skin cancer in dogs [1]. There is a high variable biologic behavior of MCT in dogs, which may be presented as solitary masses, which can be cured with surgical resection, or as a metastatic and fatal disease [2]. Prognostic indicators associated with outcome in dogs are histological grade, age, breed, gender, tumor location, time before excision, size, presence of tumor ulceration, number of tumors, recurrence, metastasis, mitotic index, Ki-67 expression, IMVD, aberrant KIT protein expression and KIT mutation [3-8].

MCT affects mainly middle aged and older dogs, with an average of nine years old $[7,8]$. Most commonly affected breeds include Boxer, Boston Terrier, Collie, Bull Mastiff, Labrador Retriever, Golden Retriever, Pug, Vizsla, Miniature Poodle, Weimaraner, Chinese Shar Pei, Rhodesian Ridgeback and German Shepherd [1].

Until recently, there were no data in the literature regarding gender predilection or association between gender and survival rate in dogs with cutaneous MCT, except for one study, in which shorter survival time has been observed in males treated with surgical excision [5].

"Corresponding author.
In a recent study, authors showed correlation between gender and histologic grades, in which females had mainly low grade tumors [9].

Main histological grading scheme was proposed by Patnaik et al. (1984). However, due to discordance (50.3\%) among pathologists in grading MCT [10,11], a more objective scheme was developed by Kiupel et al. (2011). A new prognostic classification for MCT was proposed, based on KIT pattern. Three distinct patterns of protein localization in neoplastic mast cells have been identified, which are membranous, diffuse cytoplasmic and focal cytoplasmic. These patterns were correlated with tumor aggressiveness and dogs that had a focal or diffuse cytoplasmic pattern showed an unfavorable prognosis [3].

$\mathrm{Ki}-67$ expression is widely used to assess cell proliferation, since it has shown prognostic value in MCT cases $[5,12,13]$. Some authors used cell proliferation rate to separate MCT grade 2 in two subgroups with markedly different survival times. It has been suggested that protein Ki-67 should be routinely analyzed in animals with MCT, along with other prognostic markers such as histological grade and KIT pattern [14]. Proliferative activity determined by immunohistochemical staining 
can also be associated with susceptibility to chemotherapy of tumors, since the most commonly used anticancer drugs act in cell division $[14,15]$.

Intratumoral microvessel density (IMD) is a parameter used to assess angiogenesis, which is regulated by proand anti-angiogenic factors [16]. It can be measured by optical microscopy and its disclosure is made by using antibodies with affinity for specific epitopes of the endothelial cell, such as von Willebrand factor, also known as factor VIII [17]. Studies in veterinary medicine demonstrated the importance of IMD in animals $[18,19]$. It has been concluded that this parameter can be used as a prognostic factor in canine cutaneous MCT in the postoperative period [20].

The goal of our study was to investigate the relationship among breed, age, gender, tumor location, size, time before surgery, tumor appearance, number of tumors, metastasis, recurrence, cellular proliferation, IMVD and apoptotic index with histological grade and KIT protein localization.

\section{Materials and Methods}

\subsection{Materials}

Twenty-eight canine cutaneous MCT from twenty dogs were included in this study. All dogs were attempted at the Veterinary Teaching Hospital at Sao Paulo State University and were included on the basis of the following inclusion criteria: 1) confirmed diagnosis of canine cutaneous MCT; 2) treatment with surgical excision (no chemotherapy prior to surgery); 3) adequate formalin-fixed paraffin embedded material available for histological grade and immunohistochemical staining.

\subsection{Methods}

Data including age, breed, gender, time before surgery, tumor location, tumor ulceration, number of tumors (single or multiple-in which a nodule grew within a $10 \mathrm{~cm}$ radius of the original tumor), as proposed by Murphy et al. (2006), [21] survival time and cause of death were recorded. All masses were measured in three dimensions. We performed regional lymph node aspirates, following the criteria described by Krick et al. (2009), abdominal ultrasound and thoracic radiography. All dogs underwent surgical procedure. Follow-up information was obtained through rechecks and phone calls. Diagnosis and histological grade of MCT were based on Patnaik et al. histological grading system (1984) and on Kiupel et al. (2011). Mitotic index was assessed according to Romansik et al. (2007). For dogs with multiple tumors with different histological grades, only the highest histological grade was considered (the less histologically differentiated) for the analysis and for all other parameters.

Three-micrometer sections of formalin-fixed paraffin- embedded tissue were cut, deparaffinized in xylene, rehydrated in graded ethanol, and rinsed in distilled water. The primary antibody used were anti-human Von Willebrand's factor (Dako Cytomation, Carpenteria, CA), anti Ki-67 (MIB1; Dako Cytomation, Carpenteria, CA), cleaved caspase-3 (Asp 175, Neomarkers) and anti c-KIT antibodies (Dako Cytomation, Carpenteria, CA) diluted (1:2000; $1: 50 ; 1: 50$ and 1:400, respectively) in antibody diluent (Dako). Following deparaniffization and hydration, antigen retrieval was performed using $10 \mathrm{mM}$ citrate buffer solution, $\mathrm{pH}$ 6.0, in a pressure cooker $\left(\mathrm{Pascal}^{\mathbb{B}}\right.$ Dako) at $121^{\circ} \mathrm{C}$ for three minutes. Endogenous peroxidase was blocked by $3 \%$ hydrogen peroxide in methanol for 20 minutes. Next, the material was kept for one hour, at $27^{\circ} \mathrm{C}$, in skim milk powder $\left(\right.$ Molico ${ }^{\circledR}$ ) diluted to $3 \%$ with deionized water. In a wet chamber, the slides were incubated in primary antibody for 18 hours (overnight) at $4^{\circ} \mathrm{C}$. Advance HRP (Dako) was used as the secondary reagent according to the instructions of the manufacturer. The slides were washed with TRIS buffered solution, $\mathrm{pH}$ 7.4, between the steps. Reactions were revealed with a ready-to-use DAB solution (Dako) for five minutes. Slides were stained with hematoxylin, dehydrated, and mounted. Sections from normal canine lymph node were used as positive control for both Ki-67 and cleaved caspase-3; hemangiosarcoma for Von Willebrand's factor and skin of allergic dogs sections for c-KIT. Under the same conditions, negative controls were incubated in mouse immunoglobulin (Dako) without primary antibody.

KIT immunohistochemical staining was evaluation as previously described [3]. Focal and diffuse cytoplasmic patterns were gathered, since both have similar prognosis $[3,22]$. For Ki-67 immunohistochemical staining evaluation, areas with the highest proportion of immunopositive neoplastic mast cells were identified at $400 \times$ magnification. Only slides with at least one positive cell as an internal positive control was considered in the study. The cut-off value for Ki-67 was 23 , as proposed by Webster et al. (2007). In order to determine apoptotic index (caspase 3), we counted all positive and negative cells in five fields at $400 \times$ magnification. To assess the IMVD, five fields were selected, which corresponded to 265041.03 micrometer area each, captured by a computerized image analyses system (Leica QWin 3.0 version), at 200× magnification. We obtained the corresponding vessels area in each field, and the IMVD was than expressed as the percentage area identified.

\subsection{Data Analysis}

Log-rank model was used to compare survival rate with histological grade and immunohistochemistry findings. According to the medium value of the IMVD and apoptotic index, tumours were divided into low and high 
groups. Median survival time was calculated using the Kaplan-Meier. For all analysis, a 5\% level of significance was considered using the software GraphpadPrism 3.0 .

\section{Results}

From the 20 dogs, eight breeds were represented: Boxer $(\mathrm{n}=5)$, Labrador $(\mathrm{n}=3)$, American Pit Bull $(\mathrm{n}=3)$, Fila Brasileiro $(n=2)$, Dachshund $(n=1)$, Doberman pinscher $(n=1)$, Poodle $(n=1)$, Great Dane $(n=1)$ and there were 3 cross breed dogs. There were twelve males $(60 \%)$ and eight females $(40 \%)$. The median age at the time of the surgery was 100 months (range, $60-168$ months).

Tumors were located on the limbs $(\mathrm{n}=14)$, trunk $(\mathrm{n}=$ $8)$, head $(n=3)$, perineal area $(n=3)$. Median tumor size was $39 \mathrm{~cm}^{3}$ (range, $1-640 \mathrm{~cm}^{3}$ ). Time elapsed between observation and removal of tumor ranged between 5 and 1080 days. Seven (35\%) ulcerated tumors were histologically high grade ones (Kiupel et al., 2011). 75\% of them $(5 / 7)$ were high grade tumors. Moreover, 5/7 ulcerated tumors showed cytoplasmic staining associated KIT protein. The number of tumors in the same animal was related to histological grade, since all multiple tumors were low grade.

According to Patnaik's grading system, $10 \%$ of the tumors $(2 / 20)$ were grade I, 80\% (16/20) grade II, and $10 \%(2 / 20)$ grade III. Using Kiupel et al. (2011) grading system, 70\% (14/20) was low grade tumors and 30\% $(6 / 20)$ high grade tumors. Twelve $(60 \%)$ tumors presented a cytoplasmic kit staining pattern, while eight $(40 \%)$ had perimembranous kit staining pattern. Six (46\%) tumors showed less than twenty-three Ki-67 positive cells, seven $(54 \%)$ had more than 23 positive cells for $\mathrm{Ki}-67$ and seven were not considered since there were no positive neoplastic mast cells, neither keratinocytes which were positive internal control. There was a relationship $(\mathrm{p}<0.05)$ between kit expression and increased cell proliferation. The average IMVD was 5.74\% $\pm 5.70 \%$ $(0.50 \%$ to $7.81 \%)$. There was a significant difference in IMVD between low and high grade tumors. The majority $(11 / 12)$ of low grade tumors showed low IMVD. There was evidence of recurrence in eleven (55\%) dogs, and 9 of them presented kit cytoplasmic staining. We observed a rate of $8 \%$ of lymph node metastasis. Survival rate related to recurrence, metastasis and histological grade. Results are shown on Table 1.

\section{Discussion}

No significant associations were found between the breed of the dogs and other variables studied. Some authors state that Boxers appear to develop MCT at a younger age and tend to have less aggressive tumors [8,23]. However, in our study most Boxers were older, but all of them presented grade II and only one had a high grade tumor according to the new proposal system.

Interval between observation and removal of tumor ranged from 5 to 1080 days $(\mathrm{Mi}=150$ days $)$ and most dogs (9/10) with time before excision higher than 150 days had low grade tumors or grades I and II according to Patnaik. Dogs with tumors presented for months prior to surgery tend to do well, in accordance to other authors [24].

Tumor location was not an important prognostic indicator; however, both dogs with tumors on inguinal/perineal region had high grade tumors and died four months after the diagnosis. Comments in the veterinary literature regarding the prognostic significance of this parameter are controversial. MCTs arising in the inguinal/perineal, claw bed, oral, muzzle and mucocutaneous region are commonly regarding as having a worse prognosis compared with MCT arising on other regions [7,8,25]. It has been stated that there was no significant association between tumors location and additional MCT development or survival time [4,26].

The association observed between ulcerated tumors and histological grade may be due to a high cellular proliferation rate. It is accepted that angiogenesis is important for tumoral progression [27]. Nevertheless, tumor blood vessels become abnormal in almost all aspects of their function and structure [28], which may impair tissue perfusion on tumoral periphery and may cause ulceration. Previous studies described an important correlation of ulcerated tumors and cellular proliferation rate and aberrant kit expression, which are both important for tumoral differentiation and progression and also a relationship between more aggressive tumors and ulceration [8,22].

A significant finding of our study is the association of multiple synchronous MCT at the time of diagnosis with histological grade, since all of them had low grade tumors. Previous studies did find a similar association regarding that these dogs tend to present low metastasis rate and larger survival rates [29,30]. However, Kiupel et al. (2005) found decreased survival time in dogs with multiple synchronous MCT. In our study there was no association of number of tumors with survival rate as demonstrated also in a large study with 280 MCT cases in dogs [31].

We observed a significant higher IMVD in high grade tumors than in low grade ones. These results could indicate an increased angiogenic activity related to tumor differentiation. It has been also concluded that IMVD is an important prognostic indicator for MCT and it was related to invasiveness and mitotic index [20]. Results have highlighted a strong association between cytoplasmic KIT 
Table 1. Correlation between clinical pathologic variables and classification systems used in the diagnosis of canine cutaneous MCT.

\begin{tabular}{|c|c|c|c|c|c|c|c|c|c|c|}
\hline \multirow{3}{*}{ Variable } & \multicolumn{10}{|c|}{ Canine cutaneous MCT $(\mathrm{N}=$ number of samples $)$} \\
\hline & \multicolumn{4}{|c|}{ Grade Patnaik et al. (1984) } & \multicolumn{3}{|c|}{ Grade Kiupel et al. (2011) } & \multicolumn{3}{|c|}{ KIT protein Webster et al. (2004) } \\
\hline & 1 & 2 & 3 & $\mathrm{p}^{*}$ & Low & High & $\mathrm{p}^{*}$ & Memb & Citopl & $\mathrm{p}^{*}$ \\
\hline \multicolumn{11}{|l|}{ Age } \\
\hline$\leq 100$ months & 2 & 7 & 1 & $>0.05$ & 8 & 2 & $>0.05$ & 5 & 5 & $>0.05$ \\
\hline$>100$ months & 0 & 9 & 12 & & 6 & 4 & & 3 & 7 & \\
\hline \multicolumn{11}{|l|}{ Gender } \\
\hline Male & 2 & 9 & 1 & $>0.05$ & 9 & 3 & $>0.05$ & 5 & 7 & $>0.05$ \\
\hline Female & 0 & 7 & 1 & & 5 & 3 & & 3 & 5 & \\
\hline \multicolumn{11}{|l|}{ Breed } \\
\hline Boxer & 0 & 5 & 0 & & 4 & 1 & & 3 & 2 & \\
\hline Other & 2 & 9 & 11 & $>0.05$ & 8 & 4 & $>0.05$ & 3 & 9 & $>0.05$ \\
\hline \multicolumn{11}{|l|}{$T B S^{*}$} \\
\hline$<150$ days & 1 & 7 & 2 & $>0.05$ & 5 & 5 & $>0.05$ & 2 & 8 & $>0.05$ \\
\hline$\geq 150$ days & 1 & 9 & 0 & & 9 & 1 & & 6 & 4 & \\
\hline \multicolumn{11}{|l|}{ Size } \\
\hline$<39 \mathrm{~cm}^{3}$ & 2 & 8 & 0 & $>0.05$ & 8 & 2 & $>0.05$ & 2 & 8 & $>0.05$ \\
\hline$\geq 39 \mathrm{~cm}^{3}$ & 0 & 8 & 2 & & 6 & 4 & & 6 & 4 & \\
\hline \multicolumn{11}{|l|}{ Ulcerated } \\
\hline Yes & 0 & 6 & 1 & $>0.05$ & 2 & 5 & $<0,05$ & 2 & 5 & $>0.05$ \\
\hline No & 2 & 10 & 1 & & 12 & 1 & & 6 & 7 & \\
\hline \multicolumn{11}{|l|}{ Number } \\
\hline Single & 1 & 9 & 2 & $>0.05$ & 6 & 6 & $<0,05$ & 4 & 8 & $>0.05$ \\
\hline Multiple & 1 & 7 & 0 & & 8 & 0 & & 4 & 4 & \\
\hline \multicolumn{11}{|l|}{$\mathrm{Ki}-67$} \\
\hline$<23$ & 0 & 6 & 0 & $>0.05$ & 6 & 0 & $>0.05$ & 5 & 1 & $<0.05$ \\
\hline$>23$ & 1 & 5 & 1 & & 3 & 4 & & 1 & 6 & \\
\hline \multicolumn{11}{|l|}{ Mitotic index } \\
\hline$<5$ & 2 & 13 & 0 & $<0.05$ & 14 & 1 & $<0.05$ & 7 & 8 & $>0.05$ \\
\hline$>5$ & 0 & 3 & 2 & & 0 & 5 & & 1 & 4 & \\
\hline \multicolumn{11}{|l|}{ IMVD } \\
\hline$<5.74 \%$ & 1 & 111 & 0 & $>0.05$ & 11 & 1 & $<0.05$ & 6 & 6 & $>0.05$ \\
\hline$\geq 5.74 \%$ & 1 & 5 & 2 & & 3 & 5 & & 2 & 6 & \\
\hline \multicolumn{11}{|l|}{ Metastasis } \\
\hline Yes & 0 & 0 & 1 & $>0.05$ & 0 & 1 & $>0.05$ & 0 & 1 & $>0.05$ \\
\hline No & 2 & 16 & 1 & & 14 & 5 & & 8 & 11 & \\
\hline \multicolumn{11}{|l|}{ Recurrence } \\
\hline Yes & 0 & 9 & 2 & $>0.05$ & 6 & 5 & $>0.05$ & 2 & 9 & $>0.05$ \\
\hline No & 2 & 7 & 0 & & 8 & 1 & & 6 & 3 & \\
\hline
\end{tabular}

${ }^{*}$ Time before surgery.

pattern and increased KI-67 expression. These findings are similar to the ones described by collegueas, who be- lieve that a downstream consequence of c-kit mutations and aberrant kit protein localization may be an increase 
in cellular proliferation $[14,22]$.

It is important to emphasize that eleven (55\%) dogs showed recurrence, which was associated with survival rate, as described 2006 [32]. There was predominance $(9 / 11)$ of cytoplasmic kit pattern on these samples. Some authors also correlated this pattern to high recurrence rate and shorter survival rate [33]. Survival time was associated with histological grade, according to both criteria used $[34,35]$. Based on the new proposal grading system, dogs with high grade tumors tend to die in four months after the diagnosis and our results confirmed these findings, with an exception of a Boxer breed dog with a high grade tumor, KI-67 expression $>23$ cells counts and cytoplasmic kit pattern [35]. This dog highlights that, to date, no single marker will definitely distinguish the prognosis in cases of canine cutaneous MCT, since despite the fact of caring negative prognostic indicators, be a spayed female and presented an ulcerated tumor, it survived 22 months.

We observed evidence of lymph node metastasis in $8 \%$ of dogs, which was associated with shorter survival rates. It supports previous results on veterinary literature [23]. However, we believe that it has been underestimated, since we did not performed liver and spleen cytology, as recommended on literature [36]. A recent study revel that ultrasound sensitivity to identified spleen and liver metastasis was $43 \%$ and $0 \%$ respectively, which may have inferred in false negative results [37].

\section{Conclusion}

Our results support previous studies that have shown the prognostic significance of histological grade in canine MCT. However, it should not be evaluated as a single prognostic factor for canine MCT. We recommend that cutaneous MCT in dogs should be evaluated with additional prognostic markers such as aberrant kit protein localization, IMVD, cellular proliferation, presence of ulceration, number of tumors, recurrence and metastasis, which add important information related to dogs outcome.

\section{Acknowledgements}

The first author was supported by a scholarship of Fundação de Apoio à Pesquisa do Estado de São Paulo. The authors are thankful to Rafael Torres Neto for establishing the histological grade of tumors samples.

\section{REFERENCES}

[1] J. A. Villamil, C. J. Henry, J. N. Bryan, M. Ellersieck, L. Schultz, J. W. Tyler and A. W. Hahn, "Identification of the Most Common Cutaneous Neoplasms in Dogs and Evaluation of Breed and Age Distributions for Selected Neoplasms," Journal of the American Veterinary Medical
Association, Vol. 239, No. 7, 2011, pp. 960-965. doi:10.2460/javma.239.7.960

[2] J. D. Webster, V. Yuzbasiyan-Gurkan, D. H. Thamm, E. Hamilton and M. Kiupel, "Evaluation of Prognostic Markers for Canine Mast Cell Tumors Treated with Vinblastine and Prednisone," BMC Veterinary Research, Vol. 4, 2008, p. 32. doi:10.1186/1746-6148-4-32

[3] J. D. Webster, M. Kiupel, J. B. Kaneene, R. Miller and V. Yuzbasiyan-Gurkan, "The Use of KIT and Tryptase Expression Patterns as Prognostic Tools for Canine Cutaneous Mast Cell Tumors," Veterinary Pathology, Vol. 41, No. 3, 2004, pp. 371-377. doi:10.1354/vp.41-4-371

[4] M. Kiupel, J. D. Webster, R. A. Miller and J. B. Kaneene, "Impact of Tumour Depth, Tumour Location and Multiple Synchronous Masses on the Prognosis of Canine $\mathrm{Cu}$ taneous Mast Cell Tumours," Journal of Veterinary Medicine. Series A, Physiology, Pathology, Clinical Medicine, Vol. 52, No. 6, 2005, pp. 280-286.

doi:10.1111/j.1439-0442.2005.00726.x

[5] T. J. Scase, D. Edwards, J. Miller, W. Henley, K. Smith, A. Blunden and S. Murphy, "Canine Mast Cell Tumors: Correlation of Apoptosis and Proliferation Markers with Prognosis," Journal of Veterinary Internal Medicine, Vol. 20, No. 1, 2006, pp. 151-158. doi:10.1111/j.1939-1676.2006.tb02835.x

[6] E. M. Romansik, C. M. Reilly, P. H. Kass, P. F. Moore and P. F. London, "Mitotic Index Is Predictive for Survival for Canine Cutaneous Mast Cell Tumors," Veterinary Pathology, Vol. 44, No. 3, 2007, pp. 335-341. doi:10.1354/vp.44-3-335

[7] S. J. Withrow and D. M. Vail, "Small Animal Clinical Oncology," 4th Edition, WB Saunders, Philadelphia, 2007.

[8] D. J. Argyle, M. M. Turek and M. J. Brearley, "Decision Making in Small Animal Oncology," Blackwell, Singapore, 2008.

[9] R. L. Amorim, "Biomarcadores Prognósticos em Mastocitomas Cutâneos Caninos, Avaliação em Lâminas de Arranjo de Matriz Tecidual (TMA)," Thesis, Universidade Estadual Paulista, Botucatu, 2011.

[10] N. C. Northrup, E. W. Howerth, B. G. Harmon, C. A. Brown, K. P. Carmicheal, A. P. Garcia, K. S. Latimer, J. S. Munday, P. M. Rakich, L. J. Richey, N. L. Steadman and T. L. Gieger, "Variation among Pathologists in the Histologic Grading of Canine Cutaneous Mast Cell Tumors with Uniform Use of a Single Grading Reference," Journal of Veterinary Diagnostic Investigation, Vol. 17, No. 6, 2005, pp. 561-564.

[11] P. Pinczowski, R. Torres-Neto, V. E. Fabris and R. L. Amorim, "Mastocitoma Cutâneo Canino: Variação da Graduação Histopatológica Entre Patologistas," Clínica Veterinária, Vol. 77, 2008, pp. 76-78.

[12] J. J. Abadie, M. A. Amardeilh and M. E. Delverdier, "Immunohistochemical Detection of Proliferating Cell Nuclear Antigen and Ki-67 in Mast Cell Tumors from Dogs," Journal of the American Veterinary Medical Association, Vol. 215, No. 11, 1999, pp. 1629-1634.

[13] J. D. Webster, V. Yuzbasiyan-Gurkan, D. H. Thamm, E. Hamilton and M. Kiupel, "Evaluation of Prognostic 
Markers for Canine Mast Cell Tumors Treated with Vinblastine and Prednisone," BMC Veterinary Research, Vol. 4, 2008, p. 32. doi:10.1186/1746-6148-4-32

[14] J. D. Webster, V. Yuzbasiyan-Gurkan, R. A. Miller, J. B. Kaneene and M. Kiupel, "Cellular Proliferation in Canine Cutaneous Mast Cell Tumors: Associations with c-Kit and Its Role in Prognostication," Veterinary Pathology, Vol. 44, No. 3, 2007, pp. 298-308. doi:10.1354/vp.44-3-298

[15] M. G. Alexandrakis, F. H. Passam, C. Dambaki, C. A. Pappa and E. N. Stathopoulos, "The Relation between Bone Marrow Angiogenesis and the Proliferation Index Ki-67 in Multiple Myeloma," Journal of Clinical Pathology, Vol. 57, No. 8, 2004, pp. 856-860. doi:10.1136/jcp.2003.013110

[16] B. Wolfesberger, Z. Tonar, K. Witter, A. Guija de Arespacohaga, M. Skalicky, I. Walter, J. G. Thalhammer and G. F. Egger, "Microvessel Density in Normal Lymph Nodes and Lymphomas of Dogs and Their Correlation with Vascular Endothelial Growth Factor Expression," Research in Veterinary Science, Vol. 85, No. 1, 2008, pp. 56-61. doi:10.1016/j.rvsc.2007.07.008

[17] G. F. M. Souza, R. A. Freitas and J. L. Miranda, "Angiogênese em Carcinoma de Células Escamosa de Língua e Lábio Inferior,” Ciência Odontológica Brasileira, Vol. 10, No. 1, 2007, pp. 12-18.

[18] R. C. Rosenthal, "The Prognostic Significance of Angiogenesis in Canine Mammary Tumors," Journal of Veterinary Internal Medicine, Vol. 14, No. 3, 2000, pp. 248249. doi:10.1111/j.1939-1676.2000.tb01161.x

[19] P. Maiolino, S. Papparella, B. Restucci and G. De Vico, "Angiogenesis in Squamous Cell Carcinomas of Canine Skin: An Immunohistochemical and Quantitative Analysis," Journal of Comparative Pathology, Vol. 125, No. 23, 2001, pp. 117-121. doi:10.1053/jepa.2001.0485

[20] R. Preziosi, G. Sarli and M. Paltrinieri, "Prognostic Value of Tintratumoral Vessel Density in Cutaneous Mast Cell Tumours of the Dog," Journal of Comparative Pathology, Vol. 130, No. 2-3, 2004, pp. 143-151. doi:10.1016/j.jcpa.2003.10.003

[21] S. Murphy, A. H. Sparkes, A. S. Blunden, M. J. Brearley and K. C. Smith, "Effects of Stage and Number of Tumours on Prognosis of Dogs with Cutaneous Mast Cell Tumours," Veterinary Record, Vol. 158, No. 9, 2006, pp. 287-291. doi:10.1136/vr.158.9.287

[22] R. M. Gil da Costa, E. Matos, A. Rema, C. Lopes, M. A. Pires and F. Gärtner, "CD117 Immunoexpression in Canine Mast Cell Tumours: Correlations with Pathological Variables and Proliferation Markers," BioMedCentral Veterinary Research, Vol. 19, No. 3, 2007, pp. 1-7.

[23] M. M. Welle, C. R. Bley, J. Howard and S. Rüfenacht, "Canine Mast Cell Tumours: A Review of the Pathogenesis, Clinical Features, Pathology and Treatment," Veterinary Dermatology, Vol. 19, No. 6, 2008, pp. 321-339. doi:10.1111/j.1365-3164.2008.00694.X

[24] J. M. Furlani, C. R. Daleck, F. A. M. Vicenti, A. B. Nardi, G. T. Pereira, A. E. Santana, D. Eurides and L. A. F. Silva, "Mastocitoma Canino: Estudo Retrospectivo,"
Ciência Animal Brasileira, Vol. 9, 2008, pp. 242, 250.

[25] T. L. Gieger, A. P. Theon, J. A. Werner, M. C. McEntee, K. M. Rassnick and H. E. V. DeCock, "Biologic Behavior and Prognostic Factors for Mast Cell Tumors of the Canine Muzzle: 24 Cases (1990-2001)," Journal of Veterinary Internal Medicine, Vol. 17, No. 5, 2003, pp. 687 692. doi:10.1111/j.1939-1676.2003.tb02501.x

[26] G. Sfiligoi, K. M. Rassnick, J. M. Scarlett, N. C. Northrup and T. L. Gieger, "Outcome of Dogs with Mast Cell Tumors in the Inguinal or Perineal Region versus Other Cutaneous Locations: 124 Cases (1990-2001)," Journal of the American Veterinary Medical Association, Vol. 226, No. 8, 2005, pp. 1368-1374. doi:10.2460/javma.2005.226.1368

[27] P. Carmeliet and R. K. Jain, "Molecular Mechanisms and Clinical Applications of Angiogenesis," Nature, Vol. 473, No. 7347, 2011, pp. 298-307.

[28] D. Ribatti and E. Crivellato, "Mast Cells, Angiogenesis and Cancer," Advances in Experimental Medicine and Biology, Vol. 716, 2011, pp. 270-288. doi:10.1007/978-1-4419-9533-9 14

[29] M. N. Mullins, W. S. Dernell, S. J. Withrow, E. J. Ehrhart, D. H. Thamm and S. E. Lana, "Evaluation of Prognostic Factors Associated with Outcome in Dogs with Multiple Cutaneous Mast Cell Tumors Treated with Surgery with and Without Adjuvant Treatment: 54 Cases (19982004)," Journal of the American Veterinary Medicine Association, Vol. 228, No. 1, 2006, pp. 91-95. doi:10.2460/javma.228.1.91

[30] R. Preziosi, G. Sarli and M. Paltrinieri, "Multivariate Survival Analysis of Histological Parameters and Clinical Presentation in Canine Cutaneous Mast Cell Tumours" Veterinary Research Communications, Vol. 31, No. 3, 2007, pp. 287-296. doi:10.1007/s11259-006-3427-9

[31] S. Murphy, A. H. Sparkes, A. S. Blunden, M. J. Brearley and K. C. Smith, "Effects of Stage and Number of Tumours on Prognosis of Dogs with Cutaneous Mast Cell Tumours," Veterinary Record, Vol. 158, No. 9, 2006, pp. 287-291. doi:10.1136/vr.158.9.287

[32] B. Seguin, M. F. Besancon, J. L. McCallan, L. L. Dewe, M. C. Tenwolde, E. K. Wong and M. S. Kent, "Recurrence Rate, Clinical Outcome, and Cellular Proliferation Indices as Prognostic Indicators after Incomplete Surgical Excision of Cutaneous Grade II Mast Cell Tumors: 28 Dogs (1994-2002)," Journal of Veterinary Internal Medicine, Vol. 20, No. 4, 2006, pp. 933-940.

[33] M. Kiupel, J. D. Webster, J. B. Kaneene, R. Miller and V. Yuzbasiyan-Gurkan, "The Use of Kit and Tryptase Expression Patterns as Prognostic Tools for Canine Cutaneous Mast Cell Tumors," Veterinary Pathology, Vol. 41, No. 4, 2004, pp. 371-377. doi:10.1354/vp.41-4-371

[34] A. K. Patnaik, W. J. Ehler and E. G. Macewen, "Canine Cutaneous Mast Cell Tumors: Morphologic Grading and Survival Time in 83 Dogs," Veterinary Pathology, Vol. 21, No. 5, 1984, pp. 469-474.

[35] M. Kiupel, J. D. Webster, K. L. Bailey, S. Best, J. DeLay, C. J. Detrisac, S. D. Fitzgerald, D. Gamble, P. E. Ginn, M. H. Goldschmidt, M. J. Hendrick, E. W. Howerth, E. B. 
Janovitz, I. Langohr, S. D. Lenz, T. P. Lipscomb, M. A. Miller, W. Misdorp, S. Moroff, T. P. Mullaney, I. Neyens, D. O'Toole, J. Ramos-Vara, T. J. Scase, F. Y. Schulman, D. Sledge, R. C. Smedley, K. Smith, P. W. Snyder, E. Southorn, N. L. Stedman, B. A. Steficek, P. C. Stromberg, V. E. Valli, S. E. Weisbrode, J. Yager, J. Heller and R. Miller, "Proposal of a Two-Tier Histologic Grading System for Canine Cutaneous Mast Cell Tumors to More Accurately Predict Biological Behavior," Veterinary Pathology, Vol. 48, No. 1, 2011, pp. 147-155. doi:10.1177/0300985810386469

[36] D. Stefanello, P. Valenti, S. Faverzani, V. Bronzo, V.
Fiorbianco, N. Pinto da Cunha, S. Romussi, M. Cantatore and M. Caniatti, "Ultrasound-Guided Cytology of Spleen and Liver: A Prognostic Tool in Canine Cutaneous Mast Cell Tumor," Journal of Veterinary Internal Medicine, Vol. 23, No. 5, 2009, pp. 1051-1057. doi:10.1111/j.1939-1676.2009.0354.x

[37] A. P. Book, J. Fidel, T. Wills, J. Bryan, R. Sellon and J. Matton, "Correlation of Ultrasound Findings Liver and Spleen Cytology, and Prognosis in the Clinical Staging of High Metastatic Risk Canine Mast Cell Tumors," Veterinary Radiology \& Ultrasound, Vol. 52, No. 5, 2011, pp. 548-554. doi:10.1111/j.1740-8261.2011.01839.x 